\title{
ANALYSIS OF TERRESTRIAL INTERFERENCE PROTECTION FROM UAS CNPC SATELLITE TRANSMITTERS
}

\author{
Robert J Kerczewski and Jeffrey D. Wilson, NASA Glenn Research Center, Cleveland, Ohio \\ William D. Bishop, Jacobs Engineering, Cleveland, Ohio
}

\begin{abstract}
Unmanned aircraft (UA) are projected to have a major impact on future aviation. Larger UA operating at altitudes above 3000 feet will require at least occasional access to non-segregated, that is, controlled airspace. In order for unmanned aircraft to be integrated into the airspace and operate with other commercial aircraft, a very reliable command and control (a. k. a. control and non-payload communications, (CNPC)) link is required. For operations covering large distances or over remote locations, a beyond-line-of-sight (BLOS) CNPC link implemented through a satellite will almost always be required. Protected aviation spectrum (aeronautical mobile satellite (route) service, or AMS(R)S) would normally be used for such a safety-critical link, however studies have shown that currently available aviation safety satellite spectrum is inadequate to support the projected BLOS CNPC link bandwidth requirements.
\end{abstract}

To address this inadequacy, the 2015 World Radiocommunication Conference studied the possible use of the Fixed Satellite Service (FSS) to provide CNPC, including possible allocations in KuBand and Ka-Band, under Agenda Item (AI) 1.5. Although UA CNPC satellite links in these bands were shown to meet operational availability and continuity requirements, a serious complication exists in that there are also terrestrial service allocations in these bands, in particular, Fixed Service (FS) pointto-point and point-to-multipoint microwave digital links. During the WRC-15 study cycle, much opposition to AI 1.5 was generated based on fears that UA CNPC satellite transmitters in these bands would impose unacceptable levels of interference to the FS receivers.

NASA analyzed the possible interference from the UA transmitters based on probable UA transmission and FS receiver characteristics, and UA traffic distributions and densities to determine conditions under which UA could operate without imposing unacceptable interference levels to the FS. Ultimately, UA power flux density transmission limits were proposed as a way to insure protection of FS receivers and further studies were prepared on the various proposals. This paper presents the results of these studies and discusses possible implications on future UA BLOS operations.

\section{Introduction}

As more potential applications for civil use of UAS continue to be identified, significant obstacles to the ability of UAS to operate in the National Airspace (NAS), in particular in non-segregated airspace, remain. These obstacles include the development of air traffic management procedures for UA, validated sense-and-avoid systems, and validated control and non-payload communication (CNPC) systems.

For CNPC, many UA applications can make use of line-of-sight (LOS) links to terrestrial ground stations. The range of these types of terrestrial CNPC systems can be extended by networking several terrestrial ground stations to cover a larger geographic area. Prototypes of such systems have been undergoing testing and evaluation [1]. Minimum Operational Performance Standards for terrestrial CNPC stems are nearing completion. For UA operations covering large distances or over remote locations, a beyond-line-of-sight (BLOS) CNPC link implemented through a satellite will almost always be required.

The International Civil Aviation Organization (ICAO) has determined that the CNPC link must operate over a protected aviation safety spectrum allocation. Therefore such allocations for this function were sought through the processes of the ITU Radiocommunication Sector (ITU-R). These efforts have been ongoing during the study cycles for the last three ITU-R World Radiocommunication Conferences (WRCs) held in 2007, 2012 and 2015. Studies were prepared to determine the amount of 
spectrum required to support both LOS and BLOS CNPC. The WRC of 2012 (WRC-12) allocated frequencies in the 5030-5091 $\mathrm{MHz}$ band to the Aeronautical Mobile (Route) Service (AM(R)S), providing spectrum to support LOS CNPC. Spectrum for BLOS CNPC has been much more elusive, with the latest effort coming at the 2015 WRC (WRC-15) under its Agenda Item 1.5 (AI 1.5) [2].

In an attempt to find an ITU-R regulatory solution for BLOS CNPC, WRC-15 AI considered the use of existing satellites of the Fixed Satellite Service (FSS), of which many operate in several bands, to provide BLOS CNPC at least until such time as dedicated satellite services in 5030-5091 $\mathrm{MHz}$ become available. Given the size of most unmanned aircraft, higher frequency bands are required in order to have antennas small enough to mount on the aircraft. Therefore the use of FSS in $\mathrm{Ku}-\mathrm{Band}(12-18 \mathrm{GHz})$ and $\mathrm{Ka}-\mathrm{Band}(26.5-40.0 \mathrm{GHz})$ for BLOS CNPC has been proposed. Military UAS operations successfully using satellite links for CNPC in these bands have been cited as demonstrating the feasibility of this approach. AI 1.5 for the 2015 WRC was established to study this proposal and the associated regulatory requirements necessary to allow such an application in those bands.

Opposition to AI1.5 was primarily based on two factors. First, the FSS bands do not carry an aviation safety spectrum allocation. The perceived precedent of allowing an aviation safety service to operate over a non-safety allocation (although there are other examples of this type of operation), as well as the difficulty of assuring that the BLOS CNPC links operated in the FSS can meet the requirements of aviation safety communications required a great deal of effort to overcome. Even after WRC-15 it remains a point of controversy.

Second, there are other allocations in portions of the FSS bands that were under consideration under AI 1.5, including the Fixed Service (FS), the Radionavigation Service (RS), and the Mobile Service (MS). These other services are terrestrial services that are currently sharing portions of the FSS bands. The addition of UAS BLOS CNPC to these bands required sharing studies to be conducted to determine that sharing of these bands by CNPC would not cause harmful interference to the existing services.
Studies on the sharing of the $\mathrm{Ku}$ - and Ka-Bands between existing services and CNPC for UAS were completed prior to WRC-15. These studies evaluated the potential impact of satellite CNPC earth station transmitters operating from UAS on the other in-band terrestrial services, and on the potential impact of other in-band terrestrial services on satellite CNPC receivers operating on UAS platforms.

The NASA Glenn Research Center performed sharing studies on the impact of satellite CNPC earth station transmitters operating from UAS on the other in-band terrestrial services to support AI 1.5 deliberations. These studies were conducted during the three-year study cycle leading up to WRC- 15 . Several iterations of these studies were required as changed or additional study parameters were introduced, or further clarifications sought, by administrations during processes of ITU-R Working Party 5B (WP5B), the ITU-R body responsible for AI 1.5.

These studies have been described in other recent reports $[3,4,5]$. As the WRC-15 study cycle drew to a close, however, agreement on the study results was not being reached. Failure to reach agreement on the underlying study parameters is a primary reason for this.

As an alternative, proposals were made to establish power flux density (pfd) limits on the emissions from the UAS CNPC transmitter, such that the maximum pfd reaching the earth would not exceed a value that would create harmful interference to the receiver of the in-band terrestrial service. Naturally, the selection of an appropriate pfd limit is itself dependent on the choice of operational parameters. As a result several different pfd limits were proposed.

As the WRC-15 study cycle was drawing to a close and WRC-15 approached, NASA provided some final analyses of the proposed pfd limits. This paper will discuss those last WRC-15 AI 1.5 analyses.

In the following sections we will review the sharing study parameters imposed on the studies, and provide an overview of the results. This will be followed by a discussion of the several proposed pfd limits and results of analyses of these limits. We will close with a brief summary of the result of WRC-15's 
deliberations on AI 1.5 and provide some final concluding remarks.

\section{Sharing Study Parameters}

The parameters applied to the sharing studies were initially established at the beginning of the WRC-15 study cycle through the actions of several ITU-R Working Parties. They are based on ITU-R reports and recommendations and on the draft new report "Technical and operational characteristics, interference and regulatory environments associated with the use of frequency bands allocated to the fixed-satellite service not subject to Appendices 30, $30 \mathrm{~A}$ and $30 \mathrm{~B}$ for the control and non-payload communication of unmanned" which was under development by ITU-R Working Party 5B but not approved by the beginning of WRC-15. The draft new report provided the operational characteristics of UA earth stations operating in the FSS bands.

As the WRC-15 study period progressed, additional study parameters for the Fixed Service stations were introduced into the study process, based on other ITU-R documents and on operational information provided by some administrations. Detailed descriptions of the study parameters are provided in $[3,4,5]$. Here we provide a brief overview of the key study parameters.

The sharing studies between the uplink transmission for the UA earth station and terrestrial Fixed Service receivers covered $14.0-14.5 \mathrm{GHz}$ and 27.5-29.5 GHz, the portions of the bands studies in WRC-15 Agenda Item 1.5 that contain Fixed Service allocations. The key transmit parameters for the UA earth station are shown in Table 1.

The UA earth station antenna was originally characterized by a Bessel-function antenna pattern. Since the Bessel function antenna is not officially recognized as an ITU-R antenna pattern applicable to the FSS, later in the study period evaluation of an ITU-R antenna pattern referred to as S.580-APLUM001 was added [6]. Figure 1 compares the antenna patterns for the Bessel function and S.580APL-UM001 antennas for the large antenna at 27.529.5 GHz. The S.580-APL-UM001 has considerable higher sidelobes and backlobes compared to the Bessel function antenna.
Table 1. UA Earth Station Transmit Parameters

\begin{tabular}{|l|l|c|c|c|}
\hline Parameter & $\begin{array}{l}\text { Antenna } \\
\text { Size }\end{array}$ & Unit & $\begin{array}{c}\mathbf{1 4 . 0} \\
\mathbf{1 4 . 5} \\
\mathbf{G H z}\end{array}$ & $\begin{array}{c}\mathbf{2 7 . 5 -} \\
\mathbf{2 9 . 5} \\
\mathbf{G H z}\end{array}$ \\
\hline $\begin{array}{l}\text { Antenna } \\
\text { Diameter }\end{array}$ & Small & $\mathrm{m}$ & 0.45 & 0.45 \\
\hline $\begin{array}{l}\text { Antenna } \\
\text { Diameter }\end{array}$ & Medium & $\mathrm{m}$ & 0.80 & 0.80 \\
\hline $\begin{array}{l}\text { Antenna } \\
\text { Diameter }\end{array}$ & Large & $\mathrm{m}$ & 1.25 & 1.25 \\
\hline $\begin{array}{l}\text { EIRP } \\
\text { density }\end{array}$ & Small & $\begin{array}{c}\mathrm{dBW} / 250 \\
\mathrm{kHz}\end{array}$ & 43.78 & 42.38 \\
\hline $\begin{array}{l}\text { EIRP } \\
\text { density }\end{array}$ & Medium & $\begin{array}{c}\mathrm{dBW} / 250 \\
\mathrm{kHz}\end{array}$ & 53.78 & 44.48 \\
\hline $\begin{array}{l}\text { EIRP } \\
\text { density }\end{array}$ & Large & $\begin{array}{c}\mathrm{dBW} / 250 \\
\mathrm{kHz}\end{array}$ & 57.68 & 48.08 \\
\hline
\end{tabular}

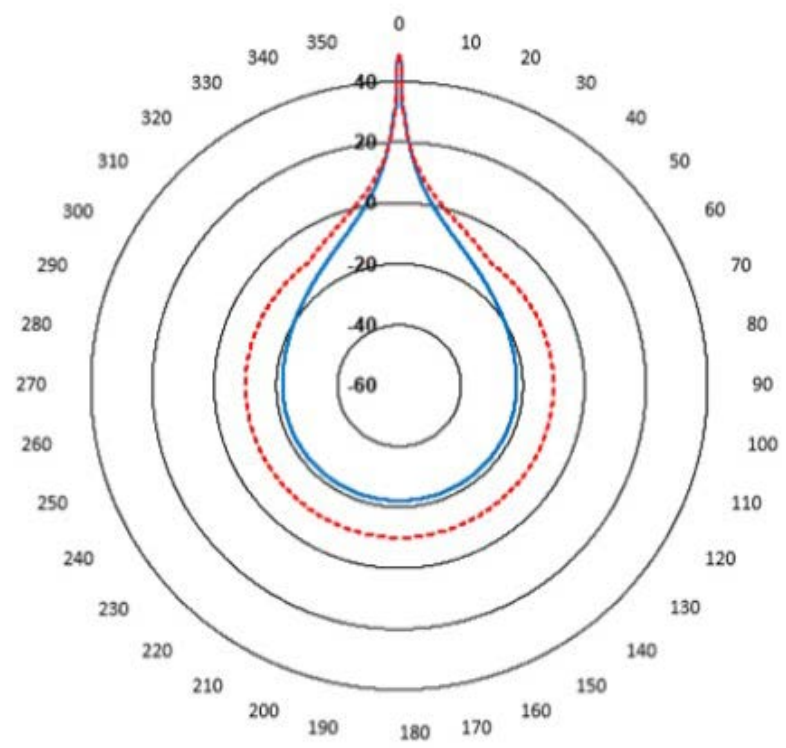

Peak-Envelope Bessel ----S.580

Figure 1 - Antenna patterns for the peak-envelope Bessel function and S.580 antennas, 27.5-29.5 GHz 
For the FS station receivers, the key parameters for the purposes of sharing studies, provided by ITUR Recommendation F.758-5, are $31.9 \mathrm{~dB}$ for 14.0$14.5 \mathrm{GHz}$ and $31.5 \mathrm{~dB}$ for $27.5-29.5 \mathrm{GHz}$, with the FS antenna pattern defined by ITU-R Recommendation F.1245-1 [7]. Later in the WRC-15 study cycle, additional antenna gains of 18, 35, 43 and $45 \mathrm{~dB}$ were added to the study for the 27.5-29.5 $\mathrm{GHz}$ band.

The protection criteria for the FS receivers are defined in terms of interference-to-noise power density $(\mathrm{I} / \mathrm{N})$, for both short-term and long-term interference, as defined by [7, 8, 9]. Later in the WRC-15 study cycle, an additional protection criterion was added for 27.5-29.5 GHz [10]. These protection criteria are described in Table 2.

The final key sharing study parameter is the density of UA. This parameter is defined by ITU-R Report M.2171 [11], which for medium and large UA are projected to have a peak density of 2.39 UA per $10,000 \mathrm{~km}^{2}$.

Table 2. Fixed Service Protection Criteria

\begin{tabular}{|c|c|c|c|}
\hline Parameter & Frequency & Value & Comments \\
\hline $\begin{array}{l}\text { Long- } \\
\text { Term I/N } \\
\text { (dB) }\end{array}$ & $\begin{array}{l}14.0-14.5 \\
\mathrm{GHz} \\
27.5-29.5 \\
\mathrm{GHz}\end{array}$ & $\begin{array}{l}-10 \\
d B\end{array}$ & $\begin{array}{l}\text { Not to exceed } \\
\text { for more than } \\
20 \% \text { of the } \\
\text { time [7] }\end{array}$ \\
\hline $\begin{array}{l}\text { Short- } \\
\text { Term I/N } \\
\text { (dB) }\end{array}$ & $\begin{array}{l}14.0-14.5 \\
\mathrm{GHz}\end{array}$ & $\begin{array}{l}+20 \\
\mathrm{~dB}\end{array}$ & $\begin{array}{l}\text { Not to exceed } \\
\text { for more than } \\
1 \times 10^{-4} \% \text { of the } \\
\text { time.[8] }\end{array}$ \\
\hline $\begin{array}{l}\text { Short- } \\
\text { Term I/N } \\
(\mathrm{dB})\end{array}$ & $\begin{array}{l}27.5-29.5 \\
\mathrm{GHz}\end{array}$ & $\begin{array}{l}+14 \\
d B\end{array}$ & $\begin{array}{l}\text { Not to exceed } \\
\text { for more than } \\
0.01 \% \text { of the } \\
\text { time in any } \\
\text { month. [9] }\end{array}$ \\
\hline $\begin{array}{l}\text { Short- } \\
\text { Term I/N } \\
(\mathrm{dB})\end{array}$ & $\begin{array}{l}27.5-29.5 \\
\mathrm{GHz}\end{array}$ & $\begin{array}{l}+18 \\
d B\end{array}$ & $\begin{array}{l}\text { Not to exceed } \\
\text { for more than } \\
0.0003 \% \text { of the } \\
\text { time in any } \\
\text { month. [9] }\end{array}$ \\
\hline $\begin{array}{l}\text { Short- } \\
\text { Term I/N } \\
(\mathrm{dB})\end{array}$ & $\begin{array}{l}27.5-29.5 \\
\mathrm{GHz}\end{array}$ & $+9 \mathrm{~dB}$ & $\begin{array}{l}\text { Not to exceed } \\
\text { for more than } \\
0.001 \% \text { of the } \\
\text { time. [10] }\end{array}$ \\
\hline
\end{tabular}

\section{Overview of Sharing Study Results}

As the WRC-15 study period progressed, a number of sharing study iterations were performed corresponding to new information and added study parameters. These studies can be grouped into three sets:

- Initial sharing studies for the general case

- Sharing studies for the worst case

- Sharing studies with additional FS parameters

Detailed results are provided in [3,5]. Here we provide an overview of those results with examples.

\section{Initial Studies, General Case}

The initial set of studies looked at the general, or average case where the FS station can vary in its configuration, such that the FS antenna can be pointing in azimuth over a range of \pm 1800 and the antenna elevation angle can vary over a range of \pm 50. The peak-envelope Bessel function antenna pattern was used to model the UA antenna. The process employed for the sharing study analyses is described in [3].

The studies were carried out by using the small and large UA antenna sizes, for both frequency bands, and testing the UA at altitudes of $3000 \mathrm{ft}$ and $19000 \mathrm{ft}$, with FS stations located at latitudes of $10^{\circ}$, $40^{\circ}$ and $70^{\circ}$. The results showed that for all cases, the long-term protection criteria were met - the received $\mathrm{I} / \mathrm{N}$ did not exceed $-10 \mathrm{~dB}$ for more than $20 \%$ of the time.

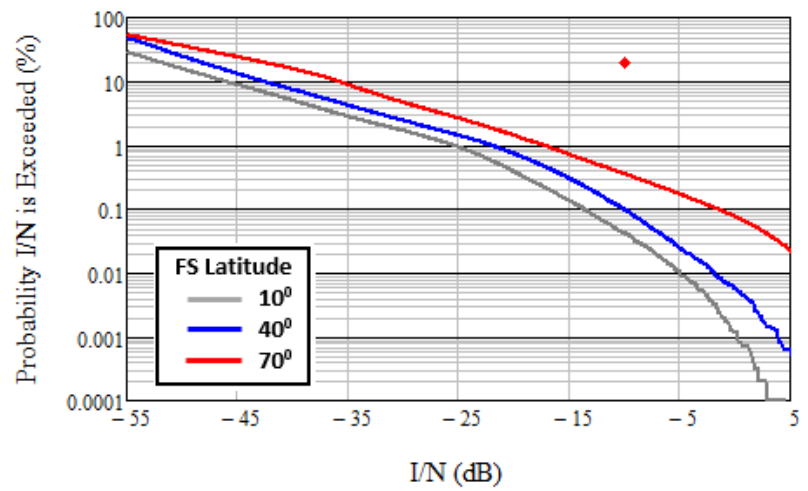

Figure 2 - Long-term analysis results for $\mathrm{Ku}$ Band with FS station at $10^{\circ}, \mathbf{4 0}^{\circ}$, and $70^{\circ}$ latitude, $\mathrm{UA}$ at $3000 \mathrm{ft}$ altitude, large UA antenna 
Figure 2 shows an example result. In this case, cumulative distribution functions are plotted for the Ku-Band case, using the large UA antenna at an altitude of $3000 \mathrm{ft}$. The worst case occurs for $70^{\circ}$ latitude, where the elevation angle of the UA antenna is lowest, resulting in the highest level UA sidelobes lobes directed toward the FS receiver on the ground. This set of curves represent the worst case for each frequency band, altitude and UA antenna size combination, and shows that the protection criterion (indicated by a red diamond) is met with a minimum of $18 \mathrm{~dB}$ of margin.

To analyze the short-term protection criteria, the analysis approach is described in [3]. Note that the short term criteria is much more stringent in terms of the amount of time for which the criteria can be exceeded, and although the I/N threshold is higher, it is more difficult to meet. It was found that the shortterm criteria can still be met, but with much less margin. Figure 3 shows the result with the smallest margin, for the Ku-Band case at $70^{0}$ latitude, $3000 \mathrm{ft}$ altitude using the large UA antenna.

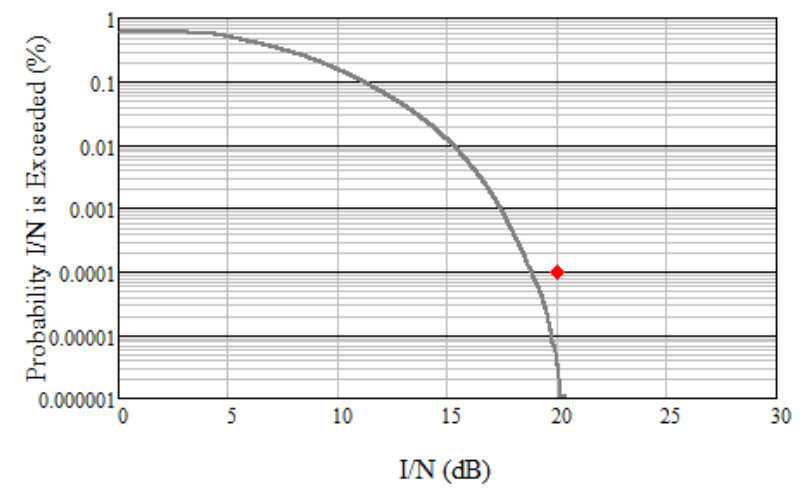

Figure 3 - Short-term analysis for Ku Band with FS station at $70^{\circ}$ latitude, UA at $3000 \mathrm{ft}$ above ground level, large UA antenna

\section{Sharing Studies for the Worst Case}

For the second main set of sharing studies, the parameters tested were restricted to the worst case. Simulations determined that the worst case is represented by: the FS and FSS satellite at which the UA is pointing are at the same longitude; the FS antenna azimuth is $0^{0}$; the FS is located at $70^{0} \mathrm{~N}$ latitude; the UA is flying at the minimum analyzed altitude of $3000 \mathrm{ft}$ altitude; and the FS elevation angle is $+5^{0}$ [4]. It should be noted that $70^{0}$ was considered the highest practical UA operating latitude when employing a geostationary satellite for the CNPC link, and therefore higher latitudes were not studied. At this point in the WRC-15 study cycle, use of the S.580-APL-UM001 antenna pattern to model the UA antenna was also introduced. The process employed for the worst case sharing studies was the same as for the general case. The results of these studies for the long-term protection criteria are shown in Figures 4 and 5.

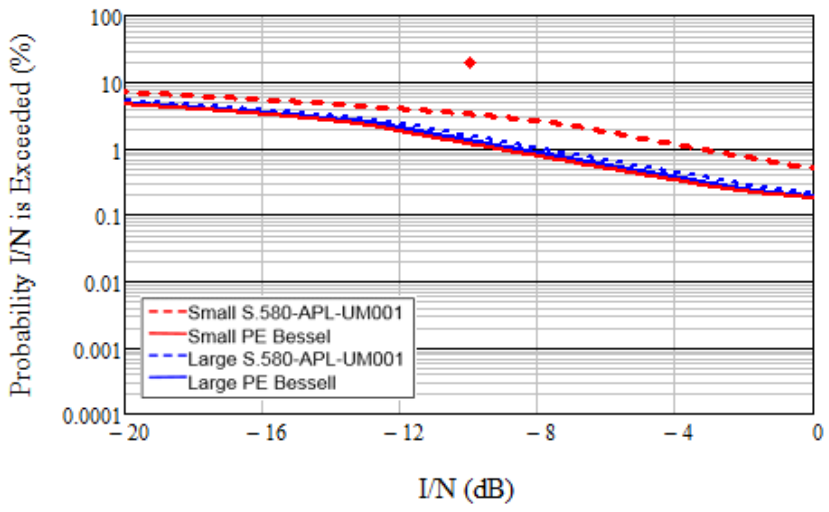

Figure 4 - Long-term analysis results for Ku Band with worst-case study parameters, for two antenna patterns and two antenna sizes.

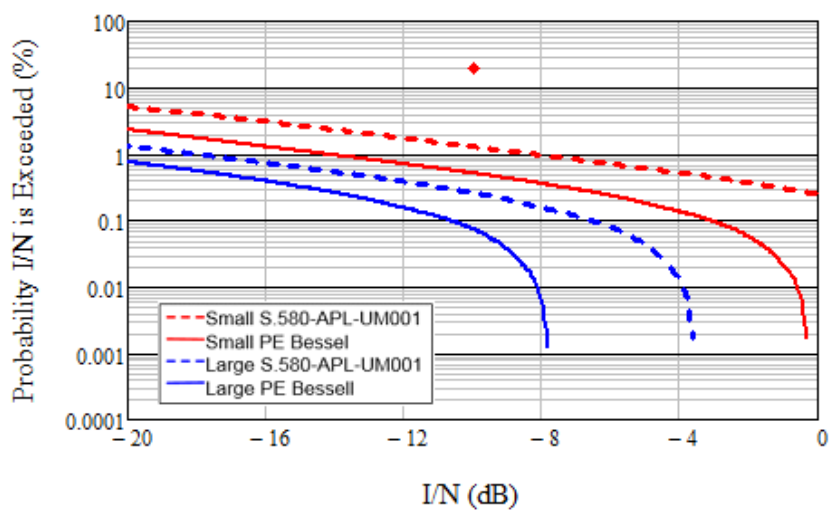

Figure 5 - Long-term analysis results for Ka Band with worst-case study parameters, for two antenna patterns and two antenna sizes.

The long-term protection criteria are met for the worst case analyses for both frequency bands, for both UA antenna patterns. The margin by which the criteria are met is considerably smaller than for the general case.

To analyze the short-term protection criteria at the worst case conditions, the analysis approach was altered to consider only whether the short-term protection criteria was exceeded, rather than the percent of time the exceedance occurred. This was to 
take into account the uncertainty of UA velocity, considering the very small time intervals involved in defining the protection criteria, which could be as small as 3 seconds in one month.

This changed the sharing study analysis to a search for UA operational conditions where the $\mathrm{I} / \mathrm{N}$ threshold could never be exceeded, rather than developing a cdf to compare to the criteria. This has a minor impact on meeting the short-term protection criteria compared to using the worst case conditions. The studies showed that for the Ka-Band case the short-term protection criteria are still met. However, for $\mathrm{Ku}-\mathrm{Band}$, the criterion could not be met at $70^{\circ}$ latitude and $3000 \mathrm{ft}$. altitude. To assure meeting the criteria, some restrictions are need on the areas of UA operation. Table 3 shows the minimum altitude at which the UA can meet the protection criterion at $70^{\circ}$ latitude, and the maximum latitude at which the UA could meet the protection criterion at $3000 \mathrm{ft}$. altitude.

Table 3. Results of short term FS protection criteria analyses for $\mathrm{Ku}$ Band $\mathrm{GHz}$

\begin{tabular}{|c|c|c|c|}
\hline $\begin{array}{c}\text { Antenna } \\
\text { size }\end{array}$ & $\begin{array}{c}\text { Antenna } \\
\text { pattern }\end{array}$ & $\begin{array}{c}\text { Min } \\
\text { altitude } \\
\text { at 70 }\end{array}$ & $\begin{array}{c}\text { Max } \\
\text { latitude } \\
\text { at } \mathbf{3 0 0 0} \mathbf{~ f t}\end{array}$ \\
\hline Small & $\begin{array}{c}\text { Peak-envelope } \\
\text { Bessel }\end{array}$ & $5000 \mathrm{ft}$ & $66^{0}$ \\
\hline Small & $\begin{array}{c}\text { S.580-APL- } \\
\text { UM001 }\end{array}$ & $9000 \mathrm{ft}$ & $48^{0}$ \\
\hline Large & $\begin{array}{c}\text { Peak-envelope } \\
\text { Bessel }\end{array}$ & $5000 \mathrm{ft}$ & $65^{0}$ \\
\hline Large & $\begin{array}{c}\text { S.580-APL- } \\
\text { UM001 }\end{array}$ & $5000 \mathrm{ft}$ & $54^{0}$ \\
\hline
\end{tabular}

\section{Sharing Studies with Additional FS Parameters}

As the WRC-15 study cycle neared its end, four additional antenna gains $(18,35,43$ and $45 \mathrm{~dB})$ were added to the study for the $27.5-29.5 \mathrm{GHz}$ band through a recommendation made by ITU-R Working Party 5C.

The analysis methodologies used for the worst case studies were applied for both the long-term and short-term FS protection criteria.
The results for the long-term studies, which applied the worst case conditions using the small and large diameter antennas and the two antenna patterns along with the four additional FS antenna gains showed that the long-term protection criteria are still met [5]. Figure 6 shows the worst of the four cases, with FS antenna gain of $45 \mathrm{~dB}$.

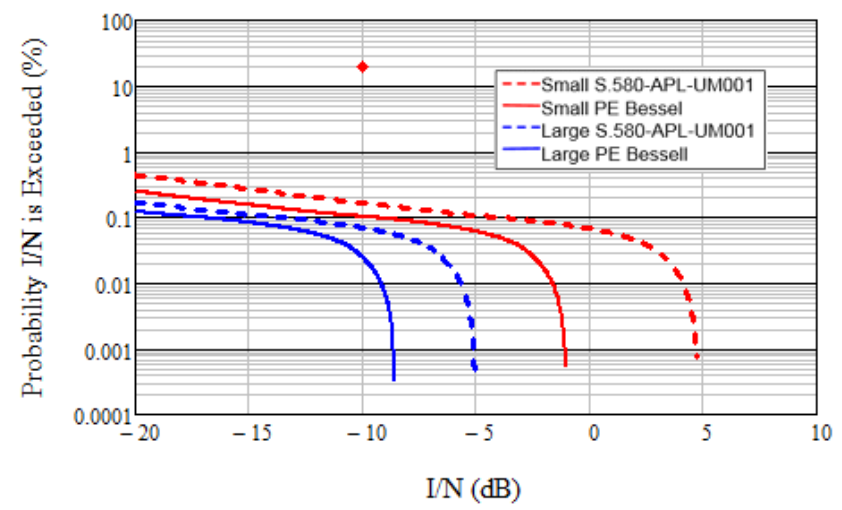

Figure 6 - Long-term analysis for Ka Band with worst-case study parameters, for two antenna patterns and two antenna sizes for FS antenna gain of $45 \mathrm{~dB}$.

For the short term protection analyses, the results were mixed. For the $45 \mathrm{~dB}$ and $18 \mathrm{~dB}$ FS antenna gain cases, the short-term criteria were met even at the worst case, for both UA antenna gain patterns. For the 43 and $35 \mathrm{~dB}$ FS antenna gain cases, some altitude and/or latitude restrictions are required to assure always meeting the criteria. The results for these two antenna gain cases are given in Table 4

Table 4 - Results of short term FS protection criteria analyses for Ka Band for 43 and 35 dB FS antenna gain cases

\begin{tabular}{|c|l|c|c|c|c|}
\hline $\begin{array}{c}\text { UA } \\
\text { Antenna } \\
\text { Size }\end{array}$ & \begin{tabular}{c}
\multicolumn{1}{c|}{$\begin{array}{c}\text { UA } \\
\text { Antenna } \\
\text { Pattern }\end{array}$} \\
\hline FS antenna gain (dB)
\end{tabular} & \multicolumn{2}{|c|}{$\begin{array}{c}\text { Min altitude at } \\
70^{0} \text { latitude }\end{array}$} & \multicolumn{2}{|c|}{$\begin{array}{c}\text { Max } \\
\text { latitude at } \\
3000 \mathrm{ft}\end{array}$} \\
\hline Small & $\begin{array}{l}\text { S.580- } \\
\text { APL- } \\
\text { UM001 }\end{array}$ & $\begin{array}{c}5000 \\
\mathrm{ft}\end{array}$ & $\begin{array}{c}6000 \\
\mathrm{ft}\end{array}$ & $57^{0}$ & $57^{0}$ \\
\hline Large & $\begin{array}{l}\text { S.580- } \\
\text { APL- } \\
\text { UM001 }\end{array}$ & $\begin{array}{c}4000 \\
\mathrm{ft}\end{array}$ & $\begin{array}{c}3000 \\
\mathrm{ft}\end{array}$ & $68^{0}$ & $70^{0}$ \\
\hline Large & $\begin{array}{l}\text { Peak- } \\
\text { envelope } \\
\text { Bessel }\end{array}$ & $\begin{array}{c}3000 \\
\mathrm{ft}\end{array}$ & $\begin{array}{c}3000 \\
\mathrm{ft}\end{array}$ & $70^{0}$ & $70^{0}$ \\
\hline
\end{tabular}




\section{Proposed Power Flux Density Limits and Analysis}

The changes and additions introduced into study parameters for WRC-15 Agenda Item 1.5 are indicative of the difficulty in gaining agreement on the draft new report in time for WRC-15. The draft new report, if approved, would have provided operational parameters for UA BLOS CNPC that would assure sufficient protection for in-band terrestrial FS stations. Without an approved report, a different approach would be needed in order to address Agenda Item 1.5 at WRC-15. Thus it was proposed to impose a power flux density (pfd) limit on UA earth stations. The pfd limit would constrain the level of emissions from the UA earth station reaching the ground, as a function of incident angle to the ground. A number of different pfd limits were proposed.

Figure 7 illustrates three of the masks under consideration for Ku-Band. Pfd Mask A is based on ITU-R Recommendation M. 1643 [12]. Pfd mask B was derived from ITU-R Recommendations F.758 and F.1245 [7]. Pfd Mask C was contributed by one administration.

Figure 8 illustrates three of the masks under consideration for Ka-Band. Pfd mask D was based on analysis of Earth Stations on Mobile Platforms (ESOMPS) from the ECC Report 184 from the European Conference of Postal and Telecommunications (CEPT) [13]. Pfd Mask E was derived from ITU-R Recommendations F.758, F.1245 and SF.1719 [7, 10]. Pfd F was proposed by one administration based on alternate FS antenna gains and ITU-R Recommendation SF.1719.

Simulations were performed with Visualyse Professional Version 7 software [14] with the FS at a fixed location of $51^{0} \mathrm{~N}$ latitude. This location correspond to the northernmost point of France which contains a high concentration of FS stations. The position of the UA varied over latitudes north of the FS to give the corresponding angles required to obtain a full range of results and using the worst case parameters defined above.

For the $\mathrm{Ku}$ Band case, three simulations were performed using the large UA antenna, employing the peak-envelope Bessel function antenna pattern at altitudes of $3000 \mathrm{ft}$. and $10000 \mathrm{ft}$., and the S.580APL-UM001 antenna pattern at an altitude of $3000 \mathrm{ft}$. The results of these simulations are plotted in Figure 7. All cases simulated fall below pfd Mask B everywhere, but not below pfd Mask $\mathrm{C}$ at angles below $11^{0}$. Pfd Mask A is not met anywhere except

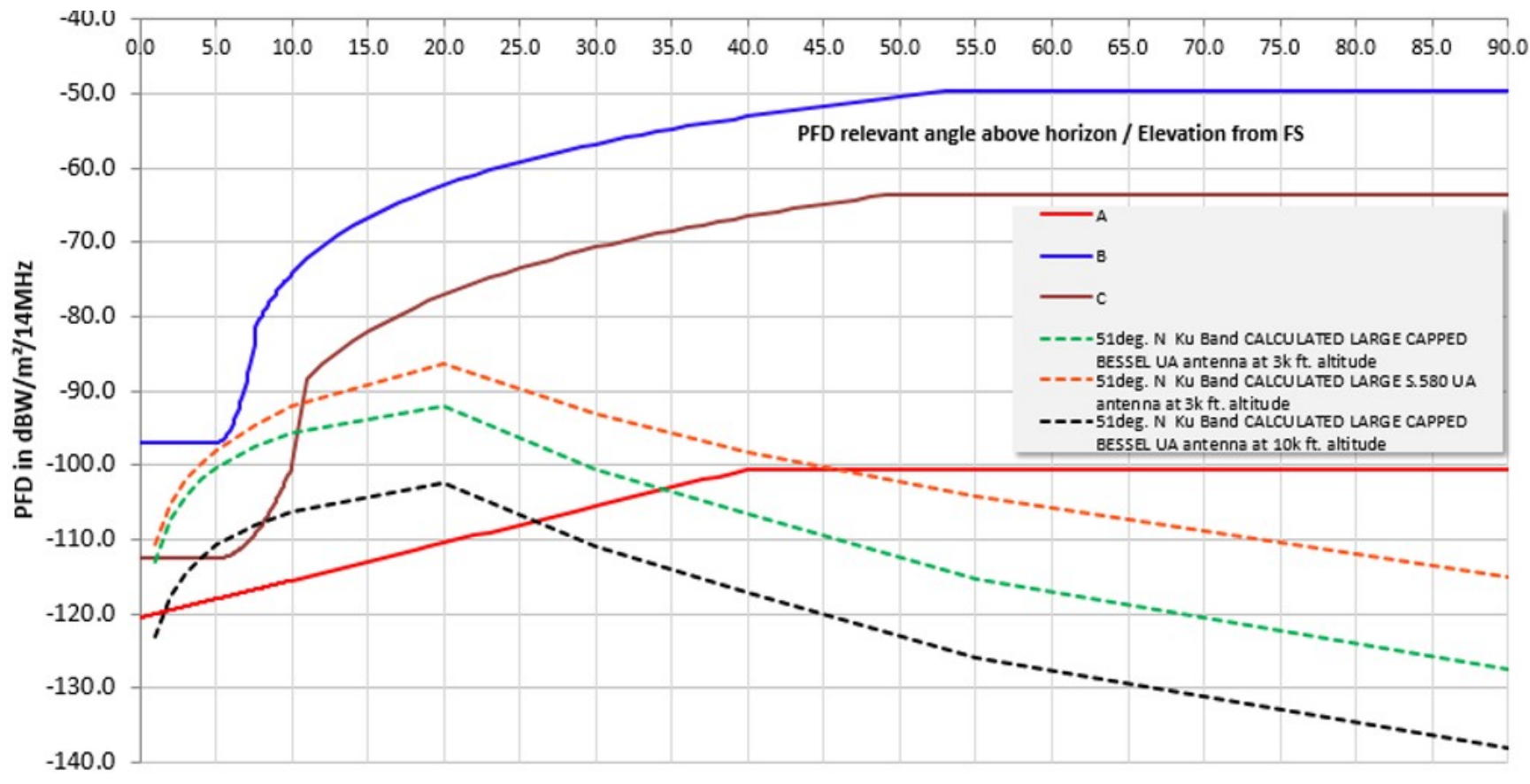

Figure 7 - Proposed pfd limit masks and simulation results (including fuselage attenuation) for Ku-Band. 


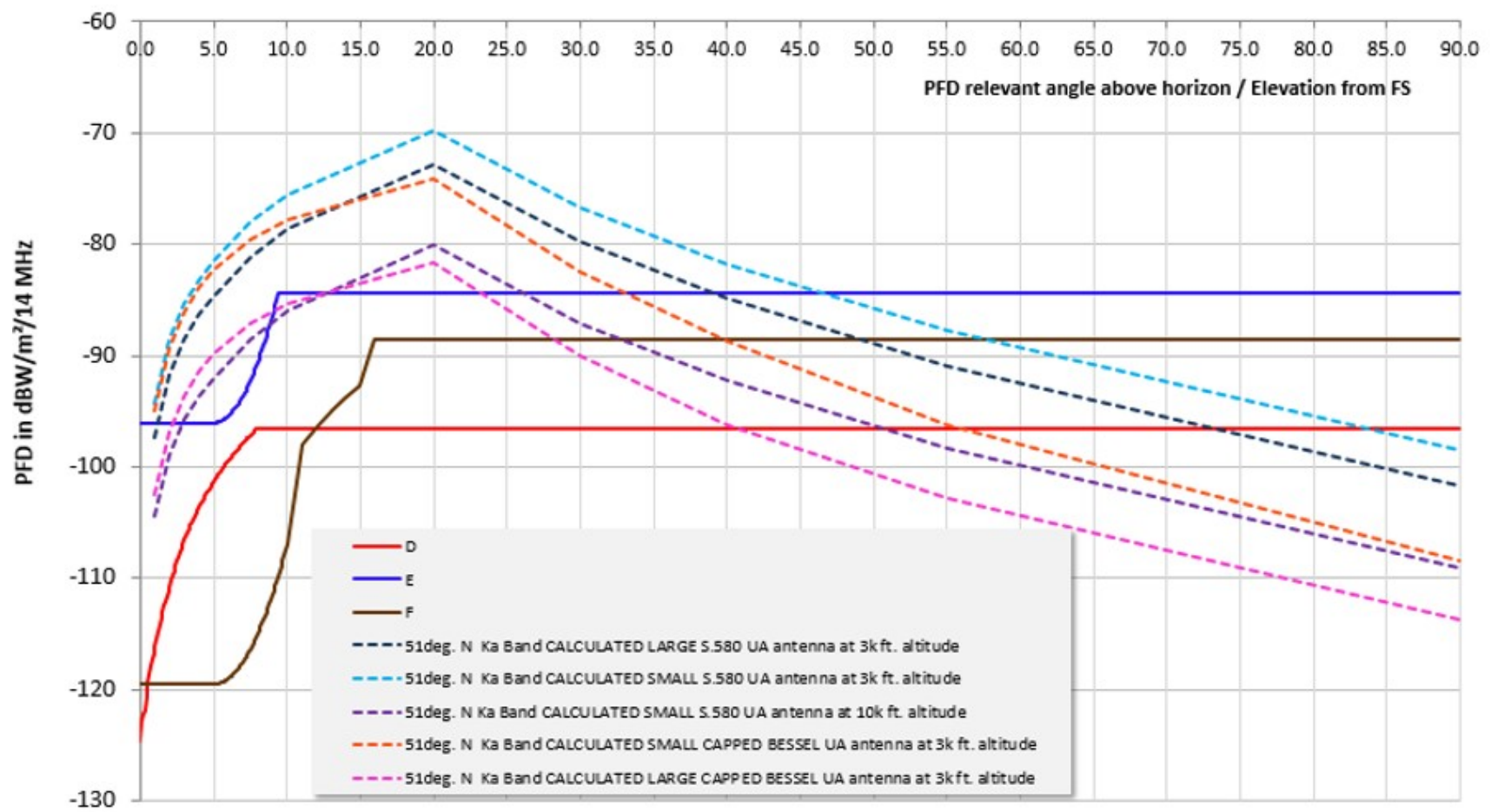

Figure 8 - Proposed pfd limit masks and simulation results (including fuselage attenuation) for Ka-Band.

for the $10000 \mathrm{ft}$ case at angles above $40^{\circ}$.

For the Ka Band case, five cases were simulated: three simulations were performed using the small UA antenna, employing the S.580-APL-UM001 antenna pattern at altitudes of $3000 \mathrm{ft}$. and $10000 \mathrm{ft}$., and the peak-envelope Bessel function antenna pattern at an altitude of $3000 \mathrm{ft}$, and two simulations were performed using the large UA at an altitude of 3000 $\mathrm{ft}$, one employing the peak-envelope Bessel function antenna pattern and the other employing the S.580APL-UM001 antenna pattern. The results of these simulations are plotted in Figure 8. All cases simulated exceed the pfd masks over a significant range of angles.

These results do not correspond well to the previous analyses, especially for the Ka-Band case, indicating further work is required to develop realistic pfd masks.

\section{WRC-15 Outcome}

Agenda Item 1.5 of WRC-15 addressed the need for radiofrequency spectrum to support BLOS CNPC requirements for UA via geostationary satellites. Since existing allocations in the aeronautical mobile satellite (route) service (AMS(R)) are inadequate to support future requirements, the use of existing satellite networks operating in the FSS in the $\mathrm{Ku}$ Band $(14 / 12 \mathrm{GHz})$ and the $\mathrm{Ka}$ Band $(30 / 20 \mathrm{GHz})$ that have potential spectrum capacity to meet the requirements for BLOS CNPC were considered in this agenda item.

At the very end of WRC-15, the conference agreed to new allocations in the FSS $\mathrm{Ku}$ and $\mathrm{Ka}$ frequency bands, identifying over $2.2 \mathrm{GHz}$ of spectrum in Resolution 155 [15]. The specific bands identified in the Resolution are:

- Space-to-Earth:

$$
\begin{array}{ll}
0 & 10.95-11.2 \mathrm{GHz} \\
0 & 11.45-11.7 \mathrm{GHz} \\
0 & 11.7-12.2 \mathrm{GHz} \text { (Region 2) } \\
0 & 12.2-12.5 \mathrm{GHz} \text { (Region 3) } \\
0 & 12.5-12.75 \mathrm{GHz} \text { (Regions } 1 \text { and 3) } \\
\hline & 19.7-20.2 \mathrm{GHz} \text { (space-to-Earth) }
\end{array}
$$

- Earth-to-space:
o $\quad 14-14.47 \mathrm{GHz}$
o $\quad 29.5-30.0 \mathrm{GHz}$ 
The Resolution specifies that this use is contingent on the successful development of ICAO SARPs, which ICAO estimates will be completed in 2020. The Resolution requires ICAO to report on its progress in the development of SARPs to WRC-19 and WRC-23.

The Resolution also requires that "power fluxdensity hard limits need to be developed for UAS CNPC links" and provides an example based on ITUR Recommendation M.1643 [12]. So further deliberations on the appropriate pfd limit will take place during the WRC-19 study cycle.

The WRC-15 was unable to agree on a pfd limit to be applied to the UA earth station. Note that the pfd limit will only be needed for the Ku-Band transmission in 14.0-14.47 GHz. The Ka Band Earth-to-space allocation of $29.5-30.0 \mathrm{GHz}$ is in a band that does not have an FS allocation. Hence the FS interference protection issue is avoided for $\mathrm{Ka}$ Band.

\section{Conclusions}

WRC-15 considered Agenda Item 1.5 which addressed the need for radiofrequency spectrum to support BLOS CNPC requirements for UA via geostationary satellites in the $\mathrm{Ku}-$ and $\mathrm{Ka}-\mathrm{Bands}$. During the WRC-15 study period, sharing studies were conducted by the NASA Glenn Research Center in support of this agenda item. The NASA studies focused on sharing between the uplink transmissions from the UA to the geostationary satellite and inband terrestrials systems operating in the FS.

NASA completed several sets of studies intended to support the development of a draft new report describing technical and operational characteristics, interference and regulatory environments for UA operating in the FSS bands under consideration.

Initial studies showed that sharing was possible between the UA and the FS, with the UA limited to operations at altitudes $\geq 3000 \mathrm{ft}$ and at latitudes $\leq$ $70^{\circ}$. As the study period progressed, additional parameters, antenna patterns and study scenarios were introduced for study. NASA produced additional studies addressing these considerations. These studies showed that for some cases further constraints would be required to allow UA operations. These constraints required higher altitude operations, lower latitude operations, or some combination of both.

Agreement was not reached prior to WRC-15 on the acceptable sharing study parameters and study results. This, among a number of other issues, resulted in the draft new report not reaching approval status. Therefore, pfd limits were introduced as an alternative to assuring protection of the FS from harmful interference. Analysis of these pfd limits, compared to the expected UA operating characteristics, was performed. The results did not correspond well to the previous study results, due to the various different technical parameters assumed in the development of the various proposed pfd limits.

WRC-15 came to an agreement on Agenda Item 1.5 and provided allocations in both $\mathrm{Ku}$ and $\mathrm{Ka}$ band for UA BLOS CNPC. However WRC-15 did not come to an agreement on a final pfd limit, but has left this issue open for further consideration. It is expected that the pfd discussion will be continued during the study period for WRC-19, which is now underway.

\section{References}

[1] Shalkhauser, K. A., J. H. Griner and Robert J. Kerczewski, September, 2013, "Flight tests of first generation prototype CNPC radio", Information Paper 06, ICAO Aeronautical Communications Panel, 29 ${ }^{\text {th }}$ Meeting of Working Group F, Nairobi, Kenya, September 2013, http://legacy.icao.int/anb/panels/acp/wgdoclist.cfm? MeetingID=296

[2] Kerczewski, R.J., Wilson, J. D. and Bishop, W. D., "Frequency spectrum for integration of unmanned aircraft”, 32 ${ }^{\text {nd }}$ Digital Avionics Systems Conference, October 2013.

[3] Kerczewski, R.J., Wilson, J. D. and Bishop, W. D., "Assessing spectrum compatibility for beyond-line-of-sight UAS control and non-payload communications”, 2014 ICNS Conference, April 2014.

[4] Kerczewski, R.J., Wilson, J. D. and Bishop, W. D., "Parameter impact on sharing studies between UAS CNPC satellite transmitters and terrestrial systems”, 2015 ICNS Conference, April 2015.

[5] Kerczewski, R.J., Wilson, J. D. and Bishop, W. D., "UAS CNPC satellite link performance - 
sharing spectrum with terrestrial systems”, 2016 IEEE Aerospace Conference, March, 2016.

[6] ITU-R Recommendation S.580-6, Radiation diagrams for use as design objectives for antennas of earth stations operating with geostationary satellites, January 2004.

[7] ITU-R Recommendation F.758-5, System parameters and considerations in the development of criteria for sharing or compatibility between digital fixed wireless systems in the fixed service and systems in other services and other interference, March 2012.

[8] ITU-R Recommendation F.1494-0, Interference criteria to protect the fixed service from time varying aggregate interference from other services sharing the $10.7-12.75 \mathrm{GHz}$ band on a coprimary basis, May 2000.

[9] ITU-R Recommendation F.1495-2, Interference criteria to protect the fixed service from time varying aggregate interference from other radiocommunication services sharing the 17.7-19.3 GHz band on a co-primary basis, March 2012.

[10] ITU-R Recommendation SF.1719-0, Sharing between point-to-point and point-to-multipoint fixed service and transmitting earth stations of GSO and non-GSO FSS systems in the 27.5-29.5 GHz band, October 2015.
[11] ITU-R Report M.2171, Characteristics of unmanned aircraft systems and spectrum requirements to support safe operation in nonsegregated airspace, December 2009.

[12] ITU-R Recommendation M.1643, Technical and operational requirements for aircraft earth stations of aeronautical mobile-satellite service including those using fixed-satellite service network transponders in the band 14-14.5 GHz (Earth-tospace), 2003.

[13] Mobile Platforms Operating with GSO Satellite Networks in the Frequency Range 17.3-20.2 $\mathrm{GHz}$ and 27.5-30.0 GHz, European Conference of Postal and Telecommunications, February, 2013

[14] http://transfinite.com/content/Professional .html

[15] Kerczewski, R. J. and Jonasson, L., "Outcomes of the 2015 World Radiocommunication Conference for Aeronautical Spectrum and Applications”, 2016 ICNS Conference, April 2016.

\author{
2016 Integrated Communications Navigation \\ and Surveillance (ICNS) Conference \\ April 19-21, 2016
}

